\title{
PROFESSORES DO CURSO DE GRADUAÇÃO EM PEDAGOGIA NA MODALIDADE EAD: USO DA BIBLIOTECA DIGITAL NA PERSPECTIVA DA LITERATURA ERGÓDICA
}

\author{
TEACHERS OF A PEDAGOGY DEGREE IN A DISTANCE EDUCATION PROGRAM: USE OF DIGITAL \\ LIBRARIES FROM THE ERGODIC LITERATURE PERSPECTIVE
}

\author{
Sindier Antônia Alves* \\ Heitor Garcia de Carvalho \\ Centro Federal de Educação Tecnológica - CEFET-MG
}

\begin{abstract}
RESUMO: O uso de bibliotecas digitais por estudantes de Pedagogia na modalidade EaD foi investigado com base nos conceitos de biblioteca digital, convencional e comportamento informacional, apoiados na concepção de Literatura Ergódica de Espen Aarseth. Neste estudo de caso, foram realizadas entrevistas semiestruturadas que têm como objetivo verificar os usos possíveis da biblioteca digital do curso. Os dados gerados pela pesquisa mostraram que os sujeitos tinham acesso à tecnologia, mas, entretanto, ainda não demonstraram um comportamento informacional próprio ou típico para a utilização das bibliotecas digitais disponíveis e relacionadas aos seus estudos.
\end{abstract}

PALAVRAS-CHAVE: biblioteca digital; comportamento informacional; literatura ergódica.

ABSTRACT: In this article, the way digital libraries are used by undergraduate students of a Pedagogy degree in a Distance Education program is researched through concepts such as digital library, print library, and informational behavior. Based upon Espen Aarseth's Theory of Ergodic Literature, this research consisted of some semi-structured interviews aiming at checking how the digital library was used in this program. The collected data showed that students did have access to technology, however they didn't showed a typical behavior when using the available digital libraries relevant to their studies.

KEYWORDS: digital library; informational behavior; ergodic literature.

\section{INTRODUÇÃO}

A chegada das tecnologias de informação e comunicação (TIC) nas escolas trazem desafios e problemas. Já as soluções dependem das potencialidades das escolas, do trabalho pedagógico desenvolvido neles por seus professores e alunos, da comunidade externa, bem como da forma que a aprendizagem é proporcionada.

A informática sozinha não pode revolucionar a educação e nem substituir o trabalho desenvolvido pela escola convencional. Deve ser considerada uma forte aliada do professor na mediação entre os alunos e o conhecimento.

De acordo com Coscarelli (2007), o uso do computador não modifica a concepção que a escola tem de aprendizagem; essa clareza deve ser do corpo docente, tendo em vista que são inúmeras as vantagens do uso do computador como recurso que auxilia o processo de ensino-aprendizagem com atividades mais interessantes e instigantes.

Então, torna-se necessário entender a realidade e providenciar uma construção coletiva de novos conhecimentos, aprendendo a lidar com as novas tecnologias, e com acesso rápido às informações e as possibilidades de interação e comunicação, com formas novas de ensinar, aprender e produzir conhecimentos. Em geral há mais de uma forma de dar solução a um problema, e são diversas as possibilidades. Nesse sentido, a inclusão digital surge como uma das possibilidades de melhorias da educação. 


\section{BIBLIOTECA DIGITAL E CONVENCIONAL}

Segundo Cunha (2008), a biblioteca digital pode ser definida como "uma coleção de informação digitalizada e organizada”, contudo, esse conceito não está consolidado devido a sua contemporaneidade ${ }^{1}$ e os itens que formam uma biblioteca digital podem ser materiais novos que surgiram já em formato digital ou material antigo que foi digitalizado.

Um documento digital pode ter uma infinidade de pontos para acesso a informação, o que amplia e torna versátil a utilização das informações que podem ser retiradas do documento. Neste sentido, Cunha (2008), apresenta a mudança do paradigma da unidade de representação da informação, passando do livro a outros formatos de representação do conteúdo, mapas, figuras, filmes, slide, verbetes, etc.

Com o incremento da globalização, a necessidade de informação do usuário deve ser atendida de forma rápida e precisa; então, a biblioteca digital traz esta discussão para o interior das bibliotecas convencionais, pois o mais importante serão as formas de acesso à informação, não importando seu tamanho em espaço físico e nem a sua localização.

Desde início do século XXI, muitos estão preferindo baixar os documentos em suas máquinas, o que facilita seu acesso e posterior leitura, o que faz com que processos de desenvolvimento de coleções e ampliação de espaço sejam repensados.

Considera-se que seja necessário refletir sobre as possibilidades de utilização das tecnologias, tanto da biblioteca digital como da convencional, pois a sobrevivência de uma não depende da extinção da outra, já que podem coexistir de forma harmoniosa. Há um potencial que a biblioteca digital apresenta como forma de acesso à informação de qualidade e de forma equânime, de modo que se faz necessária a ampliação da divulgação da mesma.

Com relação à utilização de uma biblioteca digital, ela se difere da utilização da biblioteca física, porque implica conhecimentos mais avançados sobre o uso de novas tecnologias. Conhecimentos adquiridos no trato com a biblioteca física são úteis durante uma pesquisa e utilização da biblioteca digital.

Assim, Aarseth (2005) refere-se ao fato de que cada biblioteca, seja ela física ou digital, representa ideologicamente os ideais de seus criadores (idealizadores), podendo tanto incluir quanto excluir informações relevantes ou não, servirem apenas para manutenção de um pensamento tradicional, não contribuindo para o fortalecimento da crítica aos modelos já estabelecidos.

[...] a biblioteca é mais do que livros em prateleiras; é também uma ideologia, uma ética e às diligências por trás de fornecedores de informação tais como o projecto Gutenberg e outras fontes do sistema de hipertexto da Internet conhecido como World Wide Web. Por meio dessas diligências, mantém-se a idéia da biblioteca, ainda que se substitua o médium ("a prateleira"). Mais importante ainda, nem a antiga biblioteca nem a nova estação de trabalho ligada à Internet deveriam ser encaradas como pró-canónicas ou anti-canónicas em si próprias. Ambas podem ser utilizadas para as duas finalidades opostas: preservação (inclusão) e seleção (exclusão) de informação. (AARSETH, 2005, p. 198).

Uma vez que as mudanças de paradigmas atingem a sociedade como um todo, trazendo modificações às organizações que a compõem, acreditamos é preciso que as bibliotecas tanto convencionais quanto digitais tenham repensados seus papéis e se preparem para dar respostas efetivas aos seus usuários em constante mudança.

\footnotetext{
1 Comumente, os termos biblioteca virtual ou eletrônica são usados como sendo variantes do termo biblioteca digital. O termo virtual é anterior ao digital, porém, este adjetivo como diz Tammaro (2008), significa que a biblioteca não existe de forma concreta. Atualmente este termo é menos usado, apesar de já ter sido empregado como forma de representar a nova biblioteca.
} 


\section{COMPETÊNCIA INFORMACIONAL}

A sociedade da informação (CASTELLS, 2005) faz surgir novas maneiras de pensar e se relacionar com a realidade, sendo preciso que a cultura da informação seja implementada. A information literacy, também conhecida por competência informacional, está inserida no contexto da cultura da informação.

Por competência, pode-se entender a capacidade para compreender uma situação específica, reagindo de forma adequada a ela, fazendo uma avaliação da situação, com a finalidade de atuar sobre ela da melhor forma possível. Por isso faz-se então necessário que professores graduandos desenvolvam habilidades para execução de suas tarefas do curso e também para a vida profissional, porque o educador precisa ser capaz de fazer um uso crítico do enorme volume de informações que está disponível na web, principalmente, nas bibliotecas digitais; em suma suas habilidades informacionais precisam ser bem desenvolvidas.

De acordo com Dudziak (2003) têm sido feitos muitos estudos sobre information literacy, sendo que estão surgindo novos significados para o termo. Esta utilização competente seria feita a partir da aprendizagem de técnicas, transformadas em habilidades para utilização de ferramentas de acesso à informação.

A competência informacional é transdisciplinar, pois é um processo de aprendizado constante, ligado à capacidade de elaborar significados a partir da informação. Indivíduos competentes em informação sabem reconhecer suas necessidades informacionais, como e onde encontrar tais informações, avaliando e selecionando as mais relevantes, além de organizá-las na perspectiva de criar novas interpretações. Indivíduos competentes em informação são independentes para o aprendizado, conseguem buscar a informação, fazendo uso da mesma para resolução de problemas.

\section{TEORIA ERGÓDICA DA LITERATURA}

É importante apresentar uma definição de textualidade que será aplicada neste artigo. Utiliza-se a argumentação de Aarseth (2005) que, em seu livro Cibertexto: perspectivas de literatura ergódica, analisa a textualidade de alguns objetos, dentre eles os jogos de computador. Ao definir texto, esse autor assim se posiciona:

Em vez de definir o texto como um encadeamento de significantes, à maneira dos lingüistas e semióticos, utilizo a palavra para abarcar toda uma série de fenômenos que vão de poemas breves até programas e bases de dados informáticos complexos. Como o prefixo ciber indica, o texto é encarado como uma máquina - não metaforicamente, mas como um dispositivo mecânico para produção e consumo de signos verbais. (AARSETH, 2005, p.38).

Isso significa que quanto mais complexidade apresentar as situações mais a leitura será necessária para sua solução, porque a comunicação entre usuários e máquina é geralmente textual, uma vez que sempre acontece no campo da escrita. Destacamos que a leitura é atitude essencial para a realização das tarefas na pesquisa em bibliotecas digitais.

A teoria ergódica da literatura foi desenvolvida por esse mesmo pesquisador, Espen J. Aarseth, um professor que atua no Centro de Pesquisa em Jogos de Computador na Universidade de Copenhagen na Dinamarca. A teoria ergódica da literatura foi apresentada em seu livro supracitado Cyibertext: perspectives on ergodic literature (1997), com o objetivo principal de elaborar um modelo de análise de texto que pudesse servir de base para análise de textos que, normalmente, não são levados em consideração pelos estudos da literatura. Nessa obra, o autor identifica os elementos-chave desta teoria, o que faz examinando quatro formas diferentes de ficção, a saber: o romance em formato hipertextual, o discurso multiusuário (MUD), a ficção algorítmica e os jogos de aventura.

O estudo da teoria literária foi um dos caminhos seguidos pelo autor para sua pesquisa, uma vez que os jogos, objetos de seu estudo, apresentavam características literárias. Aarseth fez várias tentativas para concluir sua pesquisa, porém, os modelos de análise usados para obras de natureza literária não foram 
suficientes para descrever grande parte dos fenômenos que ele estava estudando; contudo, não era o seu interesse apenas estudar os jogos tendo em vista a perspectiva da comunicação multimidiática ou somente adaptar os princípios de estudos da teoria literária.

Estas dificuldades fizeram com que o autor resolvesse elaborar um referencial teórico que pudesse descrever os textos os quais estava estudando, além, é claro, de poderem ser incluídos outros textos que apresentassem as mesmas características, emergindo então de seus estudos, a teoria ergódica da literatura.

Os dois termos-chave podem ser considerados neologismos. O prefixo "cyber" é indicativo de que existe um processo de interação refletido na organização do texto que envolve o midium (eletrônico ou impresso), os signos verbais e o trabalho físico e também mental do operador (leitor de texto ergódico). São estes os elementos que, de acordo com o autor, formam as engrenagens do que ele nomeou de "máquina textual". $\mathrm{O}$ leitor (operador) executa tarefas que exigem velocidade no raciocínio e perspicácia diante do texto de jogos. Segundo Aarseth, o leitor não conta somente com a imaginação e experiência prévia; deve ter capacidade para relacionar os acontecimentos, criando maneiras para "atravessar" o texto.

De acordo com Martins (2007), para Aarseth o esforço do leitor de texto ergódico não é só cognitivo, mas também físico, uma vez que, além dos movimentos que faz com os olhos e do virar das páginas de textos canônicos, manipula o teclado, o mouse, além de manipular também os fragmentos dos textos. A produção e o consumo ou leitura de informações que estão envolvidas em processos de trocas literárias são responsabilidades dos elementos que formam a "máquina textual", de acordo com as idéias de Aarseth.

O segundo neologismo surge para representar este trabalho de leitura que é físico. O termo ergódico vem do campo da física, sendo etimologicamente originário do grego: ergon (trabalho) e hodos (trajetória). A literatura ergódica é caracterizada por uma nova maneira de ler que implica num gasto de energia tanto mental quanto física do leitor. Este fenômeno estudado por Aarseth, por ser ainda uma novidade, não tem sido considerado pelos debates sobre leitura.

De acordo com o autor, o texto de ficção ergódico necessita ser experimentado pelo seu autor, antes do leitor. Sendo assim, o texto ergódico não pode ser comparado aos textos de ficção comum; sua dimensão torna-o diferente, inserindo-se em outra esfera literária. Este aspecto incomum dos textos ergódicos, segundo Aarseth, faz com que este tipo de texto tenha um comportamento diferente dos textos canônicos, sendo preciso um conhecimento prévio desta tipologia textual para que sua leitura seja compreensiva.

Esta teoria tem recebido diversas críticas de vários teóricos, os quais argumentam que este tipo de texto nada tem de diferente dos textos canônicos, apresentando três justificativas: 1) toda literatura tem caráter inédito e não-linear, pois o leitor pode dar maior ênfase em algumas passagens mais que a outras e sua transposição se dá de acordo com seu interesse; 2) o leitor, para dar sentido ao texto, estabelece suas escolhas; e, por fim, 3) há um sentido obrigatório para a leitura de um texto e este não pode ser subvertido, ou seja, a leitura será sempre feita da esquerda para a direita; portanto, o texto não poderia ser não-linear, a leitura de uma sequência de signos é feita uma de cada vez.

De acordo com Aarseth (2005) a estrutura do texto ergódico é formada por blocos de informação que estão estruturados para serem lidos de uma maneira não-linear, sem que, contudo, isso implique no estabelecimento de um caos.

O leitor apreende o texto em diversos momentos, podendo dele se distanciar enquanto consulta outros textos, o que abre novas possibilidades para leitura. Em se tratando de jogos de aventura, para o autor, as aberturas textuais não podem ser consideradas como lacunas, mas são "filtros" que foram planejados para que o leitor possa aproveitar e dar continuidade ao texto. Ou seja, só uma resposta correta do leitor pode garantir a continuidade do texto. Ele pode dar prosseguimento alterando a história. O texto canônico ao contrário apesar de possuir também lacunas, seu preenchimento não tem o poder de alterar os rumos do texto, não impedindo ou retardando o progresso do leitor. 
A leitura do texto tradicional pode ter interrupção pelo cansaço do leitor ou por sua curiosidade que o faz procurar outra fonte para complementar sua leitura. A leitura de um texto ergódico necessita sempre que aconteça uma intervenção do leitor; além disso, o leitor precisa ter habilidades para lidar com textos ergódicos.

O signo verbal ou texto ergódico é entendido por Aarseth como uma máquina, um dispositivo de produção e consumo de signos verbais. Ele não concebe o texto como um encadeamento de significantes como os linguistas, mas como fenômenos que podem variar desde poemas curtos até bases de dados ou programas complexos (AARSETH, 2005, p.38).

O cibertexto, como agora já deverá ser evidente, é a escala (ou perspectiva) ampla das textualidades possíveis encarada como tipologia de máquinas, como sistema de comunicação literária de várias formas, em que as diferenças funcionais entre as partes mecânicas desempenham um papel definitivo na determinação do processo estético. Cada tipo de texto pode ser posicionado neste campo multidimensional consoante as suas capacidades funcionais. (AARSETH, 2005, p.39).

O texto consiste num medium material e numa série de palavras, representa um dos vértices da máquina textual, de acordo com Aarseth o texto pode ser entendido como sistema que se compõe de informações que são realimentadas constantemente. Não existe uma fronteira nítida entre os elementos que formam a máquina textual; cada um se define em relação aos outros dois, sendo que a diversidade de funções que cada um pode exercer, combinada com a dos outros vértices do triângulo, é que produz a grande variedade de textos que existem. Ou Seja, o texto resulta do processo interativo que ocorre entre os três elementos: leitor/operador, signos verbais e medium material. Para Aarseth, o texto é constantemente alimentado por informações, o que faz dele um sistema. Os textos ergódicos funcionam como quebra-cabeças, nos quais toda informação é como uma peça que pode servir, ou seja, ser encaixada ou simplesmente descartada.

Diante disso, é preciso informar que o sistema de hipertexto surge como uma oposição aos textos que têm estrutura linear. Sua forma rizomática permite que o operador perceba, imediatamente, seu tópico de interesse, construindo as ligações entre as informações. É essa velocidade para as ligações que é apontada pelos teóricos do hipertexto como sendo sua maior vantagem em relação ao texto impresso. Para Aarseth, as vantagens são discutíveis, uma vez que, dependendo do sistema de hipertexto usado, pode haver dispersão do operador.

Tanto o texto tradicional quanto o hipertexto dão possibilidade para uma leitura não linear; porém, existem algumas diferenças que são ilustradas por Aarseth a partir do conceito barthesiano de tmese no qual o leitor tem a possibilidade de "quebrar" a estrutura linear do texto, atingindo a parte específica que ele desejar. O leitor não pode receber punições do autor por essa atitude, pois ela acontece de maneira independente do texto; não foi pensada pelo autor, sendo diferente do que acontece no hipertexto².

O sistema de hipertex to definido por Aarseth, referindo-se a Theodor Holm Nelsonª é um sistema onde as sequências de leituras são especificadas pelo seu autor que controla seu texto, inclusive prevendo os possíveis saltos que o operador pode dar.

Para criar o conjunto de princípios da teoria ergódica, Aarseth utiliza conceitos fundamentais da teoria literária, da semiótica literária e computacional; essa preferência se dá pelo fato de nenhuma das teorias considerarem o texto como uma "máquina", que é seu caso. Em seu texto, Aarseth reflete sobre a semiótica computacional, descrevendo em particular as inovações dos textos eletrônicos. O autor apresenta e discute a teoria de Peter B. Anderson, da qual utilizou as tipologias, mostrando que o trabalho de Anderson apesar de inovador não tem consistência para estudos mais rigorosos sobre semiótica computacional.

\footnotetext{
2 Termo criado por Theodor Holm Nelson (Ted Nelson) na década de 1960 para definir as ligações das informações dos textos com outros através de links, sendo a World Wide Web sua forma mais conhecida, porém, não sendo a única. (Grifo nosso)

3 Mais conhecido por Ted Nelson.
} 
Quanto à teoria literária, o autor destaca que existem diferenças entre os textos tradicionais e ergódicos, mas não nega o fato de que, apesar destes textos não serem estritamente narrativos, possuem algumas características que se referem à narrativa tradicional, como a estrutura de labirintos e a não-linearidade.

Outro conceito considerado importante na descrição dos textos ergódicos é o da não-linearidade. O autor considera que o texto não-linear deve ter a capacidade de apresentar diversos caminhos e que essa variedade deve ser uma necessidade do texto. Segundo o autor, os desvios devem ser previstos, pois, se um caminho for escolhido, deve ter continuidade textual. Para Aarseth, o conceito de linearidade é discutível, é um conceito que, geralmente, é atribuído ao texto impresso; e para o autor um livro tem possibilidade de ser aberto em qualquer parte, o que significa que sua leitura pode ser feita em sentido aleatório.

O autor apresenta a necessidade de se criar um novo modelo para se fazer análise de textos que se apresentam tanto em formato eletrônico quanto impressos, porém que tenham características que os diferenciem dos textos canônicos. Ou seja, para uma nova forma de apresentação textual, novos parâmetros de análise devem ser utilizados.

\section{METODOLOGiA}

Esta pesquisa caracterizou-se como um estudo de caso. Este estudo teve por objetivo verificar como os professores que estão em um curso de formação superior na modalidade EaD fazem uso da Biblioteca Digital de sua faculdade, na utilização do acervo disponibilizado pela biblioteca. A coleta de dados refere-se ao segundo semestre de 2010 e aconteceu no polo da universidade estudada, que está localizado no município de Contagem, na região metropolitana de Belo Horizonte.

Para a realização da presente pesquisa, optou-se pela utilização de um levantamento de dados no que concerne às variáveis de frequência de utilização da biblioteca digital e análise de dados que estão ligados à utilização que os alunos fazem da tecnologia durante o período cursado e seu aproveitamento para o curso.

A presente pesquisa dividiu-se em três etapas: na primeira fase, fizemos o levantamento bibliográfico para a elaboração do referencial teórico. Na segunda etapa, aplicamos o questionário com os alunos do curso de Pedagogia do polo Contagem. Obtivemos um total de 196 questionários preenchidos. Pretendíamos, com a aplicação do questionário, documentar as formas e frequências de uso da biblioteca digital pelos alunos pesquisados, bem como obter informações que pudessem indicar dados sobre seus conhecimentos de uso de tecnologias e da internet.

Tendo em vista que esta pesquisa pretendia apresentar aspectos relacionados ao uso da biblioteca digital do curso de Pedagogia, modalidade $\mathrm{EaD}$ de uma universidade virtual - polo Contagem, tendo por base a Teoria da Literatura Ergódica de Espen Aarseth, procuramos compreender, ainda, como os professores podem adquirir competência informacional durante o curso de graduação. Para essa etapa, categorias de análise foram estabelecidas para a caracterização do uso de informática do entrevistado em seu ambiente de trabalho e estudo com perspectiva de obter informações sobre suas possíveis competências e habilidades na busca por informação no meio digital.

Elaboramos o questionário fazendo uma adaptação ao questionário de Pongelupe (2004), no qual foram estabelecidas categorias para o uso de recursos tecnológicos pelos alunos tanto no ambiente de trabalho quanto em casa e na faculdade. O questionário é composto por 3 (três) partes: a primeira parte denominamos de identificação do perfil do entrevistado; a segunda parte é a de caracterização do uso de informática do entrevistado; a terceira parte trata da caracterização do uso da biblioteca digital e convencional da faculdade. Na terceira etapa fizemos a análise dos dados, tendo por base as teorias apresentadas no referencial teórico. 


\section{CARACTERIZAÇÃO DOS SUJEITOS DA PESQUISA}

Essa pesquisa teve como foco alunos que estão cursando a graduação em Pedagogia na modalidade a distância de uma universidade do Sul do país, com polo em Contagem e que estão atuando na Educação Básica.

\subsection{A Universidade}

A Universidade conta com vários cursos de graduação, sequenciais de formação específica, cursos do Sistema Presencial Conectado na modalidade à distância, mestrados acadêmicos e profissionais; curso de pós-graduação Lato Sensu. O curso de Pedagogia pesquisado faz parte do Sistema Presencial Conectado.

O sistema presencial conectado é um sistema bimodal que conta com atividades síncronas e assíncronas, com atividades presenciais transmitidas ao vivo através de teleaulas, complementadas com a aula atividade, que serve para os trabalhos em grupo e seminários, e também pelas atividades não presenciais realizadas nos ambientes virtuais de aprendizagem.

\subsection{Polo}

O seu quadro de funcionário era composto por um diretor, 12 tutores, um responsável pela administração do polo, uma secretária, dois auxiliares de secretaria, um funcionário para serviços de cópias e uma para serviços gerais.

A estrutura física era composta por uma diretoria, secretari, cantina, uma sala de informática, uma sala que seria destinada para ser a biblioteca tradicional do polo, dois banheiros, oito salas de aula, uma secretaria e um hall de entrada.

Os computadores da biblioteca são utilizados para pesquisa na biblioteca digital da faculdade e para fazer as tarefas escolares porque o laboratório de informática ainda está em fase de implantação. Apesar de possuir espaço para estudo individual, constatou-se que os alunos não fazem uso desse espaço, preferindo geralmente, o uso das mesas para estudo de grupo. O acervo de livros ainda é muito reduzido, contendo apenas alguns livros das áreas dos cursos ofertados pelo polo.

A existência de uma biblioteca convencional é uma exigência do Referencial de Qualidade para Educação Superior a Distância e encontra-se em fase de implantação. No Referencial, são informados os tipos de recursos que devem ser oferecidos aos alunos, sendo que ele versa também sobre a estrutura física. A biblioteca física é citada no tópico (IV) Avaliação - (b) avaliação institucional-instalações físicas.

Instalações físicas

a) intra-estrutura material que dá suporte tecnológico, científico e instrumental ao curso; b) infraestrutura material dos pólos de apoio presencial; c) existência de biblioteca nos pólos, com um acervo mínimo para possibilitar acesso aos estudantes à bibliografia, além do material didático utilizado no curso; d) sistema de empréstimo de livros e periódicos ligados à sede da IES para possibilitar acesso à bibliografia mais completa, além do disponibilizado no pólo. (BRASIL, 2007, p.19).

Ainda tratando da biblioteca, o Referencial comenta que é fundamental que sejam disponibilizados para os alunos, nos polos presenciais, biblioteca e laboratório de informática que tenham acesso à Internet de banda larga, sala para secretaria, dentre outras instalações, sendo que a biblioteca deve possuir acervo atual, espaços para estudos em grupo e individual, como descrito abaixo:

As bibliotecas dos pólos devem possuir acervo atualizado, amplo e compatível com as disciplinas dos cursos ofertados. Seguindo a concepção de amplitude de meios de comunicação e informação da educação a distância, o material oferecido na biblioteca deve ser disponibilizado em diferentes mídias. É importante, também, que a biblioteca esteja informatizada, permitindo que sejam realizadas consultas on-line, solicitação virtual de empréstimos dos livros, entre outras atividades de pesquisa que facilitem o 
acesso ao conhecimento. Além disso, a biblioteca deve dispor em seu grupo interno de salas de estudos individuais e em grupo. (BRASIL, 2007, p.26).

Houve uma detalhada identificação do entrevistado, considerando-se o gênero, a idade, a caracterização do uso de informática pelo entrevistado, a caracterização do uso da Internet, a caracterização do uso da biblioteca digital e convencional da faculdade.

\section{ANÁLISE E DISCUSSÃO DOS DADOS}

Em relação ao gênero, o maior número de entrevistadas é do gênero feminino (193), sendo apenas 3 (três) do gênero masculino. O total de entrevistados é de 196 do total de 245 alunos do polo no semestre pesquisado.

A idade dos entrevistados varia de 20 a 57 anos, o maior número deles concentra-se na faixa de 31 a 43 anos, seguida da faixa de 43 a 57 anos. A amostra de entrevistados mais significativa está na faixa de 31 a 50 anos de idade, ou seja, faixa de profissionais atuantes no mercado de trabalho a um tempo maior, mas há também aqueles ainda estão fora do mercado.

A pequena parcela da amostra na faixa etária acima de 43 anos é representada pelos profissionais em duas possíveis situações: primeiramente, aqueles que estão em fim de carreira, que resolveram se qualificar para terem vantagens em suas aposentadorias; em segundon lugar, aqueles provenientes da Secretaria de Educação do Estado de Minas Gerais, uma vez que ela implantou um plano de carreira (Lei 15.293/04) no qual os profissionais portadores de títulos de graduação, especialização, mestrado ou doutorado, passam a ter seus proventos reajustados de acordo com sua titulação.

Verificamos que os alunos trabalhadores na rede estadual de ensino são predominantemente mais velhos; enquanto que, dentre os que trabalham na rede particular, predominam alunos os mais novos. Já dentre os que trabalham na rede municipal de ensino, há uma distribuição mais equânime entre as faixas etárias.

Alunos trabalhando na rede particular de ensino representam 25\% dos entrevistados, enquanto que alunos trabalhando na rede estadual e municipal representam, respectivamente, $17 \%$ e $16 \%$ do total de entrevistados da mostra. Os $8 \%$ de entrevistados não atuantes nas redes citadas anteriormente são professores de aulas particulares, creches, instituições filantrópicas e projetos sociais. Do total de entrevistados, $36 \%$ não responderam a esta questão.

Do total de 196 alunos pesquisados, 92,9\% possuem computador em sua residência e fazem uso deste, ou seja, apenas 7,1\% não usam computador em sua residência.

A faixa etária que mais apresenta uso do computador na residência tem uma variação de 30 a 43 anos, ficando a faixa acima dos 43 anos com um percentual menor. Este dado sugere que entre professores mais velhos e, provavelmente, com mais tempo de atuação profissional, há um percentual mais baixo que informa sobre o uso do computador em sua residência, contrapondo-se aos de faixa etária inferior, não significando que os professores mais velhos apresentem qualquer forma de resistência ao uso do computador.

O início de utilização do computador pelos entrevistados varia de 1994 até 2010, ano em que alguns alunos começaram a frequentar o curso de Pedagogia. Quanto ao tempo de utilização do computador na semana, os dados mostram que este uso varia de 15 minutos, como menor tempo, até 35 horas, como maior tempo de uso semanal do computador na residência.

O percentual de entrevistados que usam computador no trabalho é de $35,7 \%$. Acreditamos que a utilização possa ser em atividades como lançamento de notas em diários eletrônicos. Para esta pesquisa não procuramos levantar dados sobre o uso do computador em atividades pedagógicas por não ser este o nosso foco. Quanto ao tempo de uso de computador no trabalho, esse varia de 20 minutos até 40 horas semanais. O maior tempo de uso do computador no trabalho excede o total de horas que muitos entrevistados 
trabalham em suas escolas, o que podemos justificar como sendo aqueles entrevistados que estão atuando em secretarias de escola e estão fazendo o curso com perspectiva de mudar de função na escola, ou seja, desejam mudar de atuação profissional, passando a atuar como professor. O uso do computador no trabalho inicia-se em 1987. No entanto, a maioria dos entrevistados iniciou esse uso a partir do ano de 2000, sendo que alguns dos entrevistados só começaram a usar o computador no trabalho em 2010.

Quanto ao uso do computador na faculdade, apenas 30,1\% dos entrevistados utilizam o computador em relação aos 69,9\% que não fazem uso. Apenas 33,7\% fazem acesso à biblioteca digital a partir dos computadores da faculdade em relação aos $66,3 \%$ que não acessam. Tendo em vista que a maioria dos entrevistados faz uso do computador em sua residência, somente $9,7 \%$ o utilizam em outro local.

Quanto ao uso de impressora, o percentual de entrevistados que faz uso em sua residência é de $69,4 \%$. Embora alguns dos entrevistados usem a impressora na residência desde 1994, a maioria o faz desde 2000. Em relação ao tempo de utilização da impressora na residência durante a semana, este varia de 5 minutos até 18 horas. Quanto ao uso de impressora no trabalho, apenas 36\% a utilizam, alguns desde 1998, sendo que o tempo semanal de uso varia de 20 minutos a 15 horas.

Quanto ao uso de impressora na faculdade, apenas 6,1\% declaram que fazem uso e o tempo varia de 30 minutos a 2 horas. Este dado não pode ser confirmado por observação direta, pois não foi encontrada uma impressora no polo pesquisado que fosse de uso livre pelos alunos. Em alguns casos muito especiais o aluno solicita a impressão de algum material junto à secretária do polo. O uso da impressora em outro local foi relatado apenas por 10,2\% dos entrevistados, com o tempo de utilização variando de 15 minutos a 2 horas. A facilidade para aquisição, tanto de computador como de impressora, tem proporcionado aos alunos a compra pessoal, o que pode ser um dos motivos pelos quais a utilização em outros locais apresente um percentual reduzido.

Em relação ao uso do scanner, apenas 6 entrevistados informaram que fazem uso do equipamento em sua residência, sendo que o menor tempo de uso informado foi de 10 minutos e o máximo de 6 horas. $\mathrm{O}$ uso do scanner no trabalho foi informado apenas por 28 entrevistados, e na faculdade por 4 entrevistados, muito embora durante a nossa visita ao polo não tenhamos constatado a presença de scanner para uso dos alunos. O uso em outro local foi informado por 12 entrevistados. Pelos poucos dados de utilização do scanner pelos alunos do polo, inferimos que esse aparelho ainda não é de uso comum pela maioria deles.

Com relação ao uso do gravador de CDs, 118 entrevistados informaram que fazem uso dele na residência, 24, no trabalho, 5 , na faculdade e somente 7 , em outro local. O uso do CD-ROM em casa foi relatado por 66 dos entrevistados: no trabalho o total foi de 37 relatos e, em outro local, apenas 6 entrevistados relataram o seu uso.

O quarto item da parte B investigava a oferta dos recursos pela faculdade e o nível de satisfação dos alunos com essa oferta. Os níveis apontados seriam os seguintes: alto; satisfatório; baixo; nenhum ou não sei dizer. Os equipamentos relacionados eram: computador; impressora; gravador de CD. Os dados coletados demonstram que o nível de satisfação dos alunos em relação aos recursos oferecidos pela faculdade é, em sua maioria, "satisfatório". Quanto à oferta de recursos, no primeiro semestre de 2011, foi instalado um amplo laboratório de informática com 30 computadores para uso dos alunos, incluindo ainda os que foram instalados na biblioteca tradicional do polo que são para uso dos alunos.

A sexta questão da parte B solicitava que fosse apontado o tipo de software utilizado e a freqüência desse uso, sendo citadas como frequência: somente durante o curso; diariamente; raramente; com uma frequência média e nunca. Os dados indicam que os entrevistados fazem uso pessoal de informática e já têm este uso incorporado em seu dia-a-dia. Ela está presente em seu cotidiano para as seguintes tarefas: acessar redes sociais, e-mail, informações, imagens, fazer tarefas escolares, acessar bibliotecas digitais, dentre outras. 
O número de entrevistados que nunca fizeram uso de editor de texto é muito pequeno e o total que faz uso diário representa um percentual de 42,3\% do total de entrevistados, sendo que apenas $5,6 \%$ deles informaram nunca fazerem uso de um editor de texto. Considerando que grande parte da comunicação feita com os tutores seja via Internet, os dados apresentados pelos entrevistados sobre a utilização de um editor de texto para um curso de EaD justificam um estudo mais aprofundado.

Em relação à utilização de software de apresentação do tipo "PowerPoint", os dados apresentados para uso diário é muito elevado. Estes dados, assim como os relativos à utilização de editor de texto, também precisam de mais aprofundamento.

Dividimos os usos da Internet pelos sujeitos em: uso da Internet para leitura de textos e imagens; para leitura e escrita. Na categoria "leitura de textos e imagens", destacamos o acesso à biblioteca digital: ler notícias; acesso ao Google; acesso a livros eletrônicos/e-books; e acesso ao Youtube. Dentre os entrevistados, 96\% afirmaram fazer acesso à biblioteca digital da faculdade: 84,7\% dos entrevistados procuram ler notícias na Internet; o acesso ao Google foi informado por 90,8\% dos entrevistados; o acesso a livros eletrônicos é feito por $80,1 \%$ dos entrevistados; o acesso ao Youtube foi relatado por $82,1 \%$ dos entrevistados.

Na categoria do acesso para "leitura e escrita", os itens estão assim divididos: 93,4\% acessam e-mail; 84,2\% informaram usar o msm; o acesso às redes sociais como Orkut ou Facebook foi informado por 86,2\% dos entrevistados; 95,4\% usam a Internet para atividades da faculdade, o que se justifica pelo fato do curso ser na modalidade EaD. Parece-nos estranho o fato de 4,6\% não responderem a essa questão e um pequeno percentual $(1 \%)$ de alunos nunca fizeram acesso à Internet para fazer as atividades que são via Internet. Cabe-nos perguntar como esses alunos efetuam suas atividades se essas são, impreterivelmente, via web? Arriscamos como justificativa a não familiaridade desses alunos com o uso do computador ou da Internet e a provável terceirização desse acesso, o que não significa que não façam suas atividades.

Em relação ao uso da biblioteca física da faculdade 44,4\% dos entrevistados afirmaram fazer uso, enquanto os $55,6 \%$ restantes não responderam a essa questão. É um fato curioso, uma vez que na nova unidade, o único local onde os alunos tinham acesso aos computadores era na biblioteca, pois como já citado anteriormente, o laboratório estava em fase de implantação.

Durante as visitas constatou-se que uma parcela considerável de alunos fazia uso do espaço da biblioteca, bem como de seus computadores. Porém, não se constatou, durante a visita de observação, nenhum aluno utilizando os livros da biblioteca, mesmo porque a maioria dos livros estava sendo organizada nas estantes.

$\mathrm{O}$ uso da biblioteca da escola onde trabalha foi relatado por 42,9\% dos entrevistados. O percentual de $57,1 \%$ de alunos não respondentes a essa questão pode representar os alunos que não estão atuando como professores ou servidores em uma escola ou os que realmente não fazem uso da biblioteca da escola em que trabalham. Esse fato pode ser explicado de duas maneiras: a maioria das escolas não possui bibliotecas ou o acervo direcionado ao professor é insuficientemente. $\mathrm{O}$ fato de $7,7 \%$ dos entrevistados terem afirmado frequentar bibliotecas físicas de outras faculdades nos chama a atenção. Isso se deve, provavelmente, à falta de uma biblioteca no polo que pudesse fornecer informações a partir de um acervo em papel, que a maioria já está acostumada usar. Um percentual de 92,3\% de entrevistados não respondeu a essa questão. Outro fato que também nos chama a atenção é o percentual de 9,7\% de entrevistados que afirmam frequentar bibliotecas do bairro onde moram, informando, como solicitado, os bairros nos quais estão sediadas as bibliotecas.

$\mathrm{O}$ acesso à biblioteca digital a partir da residência foi relatado por $73 \%$ dos entrevistados. O acesso a partir da faculdade foi informado por apenas $33,7 \%$ dos entrevistados. O fato de o laboratório de informática não estar disponível para os alunos talvez seja um dos motivos pelos quais mais de $50 \%$ dos entrevistados não 
informaram se fazem o acesso, considerando ainda as dificuldades pessoais impeditivas de utilização de um recurso tecnológico, particularmente quanto ao uso da biblioteca digital.

O acesso a partir do local de trabalho foi relatado por apenas 10,2\% dos entrevistados, o que se considera um número até expressivo, pelo fato de muitas escolas ainda não estarem equipadas com computadores com acesso à Internet. O acesso a partir de outro local foi informado por 7,1\% dos entrevistados.

Indagados sobre quais eram as motivações para o uso da biblioteca digital, obtivemos os seguintes resultados: do total de 170 alunos que responderam a essa questão, 11,12\% informou o acesso por curiosidade e apenas 11,8\% informou o acesso por indicação de professor. Acreditávamos que esse dado teria maior representatividade em razão da modalidade do curso e sua especificidade. A expectativa era que a maioria dos entrevistados indicaria serem incentivados pelos professores para a utilização da biblioteca digital. Porém, $87,7 \%$ dos entrevistados informaram fazer o acesso à biblioteca digital para obter informações e para realizar as tarefas escolares. Observando os dados, percebe-se que alunos na faixa etária de 31 até 43 anos são os que declaram fazer mais usa da biblioteca digital. Talvez o fato dessa faixa etária se constituir do que podemos chamar de "nativos digitais" facilite o processo de busca de informação na biblioteca digital.

Quanto à impressão de material, 13,3\% dos entrevistados afirmou imprimir "sempre", 30,1\% informou que imprime material "às vezes", 21,4\%, "raramente", e 23,5\%, "nunca". Do total de entrevistados, apenas 11,7\% não respondeu a essa questão. A impressão de material parece estar ligada ao hábito de leitura em papel, uma vez que, apesar das novidades do mercado de leitores de e-books, a leitura na tela não está estabelecida como cultura, mesmo porque os equipamentos específicos para leitura de livros digitais ainda são caros, dificultando sua aquisição pela maioria dos entrevistados. Outro fato relevante a ser considerado é que $69,4 \%$ dos entrevistados informaram o uso da impressora na residência. Do total de entrevistados, $64,3 \%$ informaram que imprimem o material para leitura, corroborando nosso comentário anterior de que os entrevistados ainda não estão acostumados com a leitura na tela. Apenas 2,0\% informaram que imprimem material para distribuição aos colegas de trabalho e, em contrapartida, apenas 1,0\% informou que distribui material para colegas de faculdade.

Dentre as atividades realizadas pelos alunos, poucas são em grupo, logo, a pouca distribuição de material para os colegas pode ser consequência desse fato. Apesar de os alunos se constituírem numa turma, as atividades são, em sua maioria, individuais, devendo cada aluno postar suas atividades em seu portifólio.

Analisando o perfil dos entrevistados por idade, não se percebe diferenças dos mais novos em relação aos mais velhos quanto à impressão para leitura, qualificando a idéia de que a idade não é fator preponderante para definir o maior ou menor grau de utilização dessa tecnologia.

O percentual de entrevistados que apresenta dificuldade para "fazer a pesquisa" é de 35,7\%; a dificuldade de utilização do programa foi relatada por 22,4\% dos entrevistados. Pelos dados levantados durante a pesquisa, consideramos que os entrevistados apresentam conhecimentos de uso de tecnologia que são suficientes para subsidiar uma pesquisa na biblioteca digital. Tendo em vista que a diferença de 13,3\% de entrevistados com dificuldade de usar o programa em relação aos que sentem dificuldades para fazer pesquisa seja muito pequena, entendemos que o fato de o entrevistado apresentar indícios de que possui competência informacional e conhecimentos do uso de tecnologias não seja suficiente para o uso eficaz e eficiente da biblioteca digital. Acredita-se que seja necessária uma maior familiaridade com o "medium”, não para utilização comum, mas para um uso que se apresenta de certa forma especializado.

Apesar de um percentual considerável de entrevistados informarem a frequência a bibliotecas convencionais, tanto as do local de trabalho, quanto as de outras faculdades, bibliotecas comunitárias e, em menor número, as bibliotecas públicas, os dados nos mostram que os conhecimentos de utilização da biblioteca física não foram transferidos para o uso de bibliotecas digitais. Não se trata aqui apenas da busca 
de informação, mas do ato de estudar a partir do uso de materiais de uma biblioteca. Queremos dizer que ao frequentarem bibliotecas físicas, ou convencionais, não transferem esse hábito para o uso da biblioteca digital.

\section{CONCLUSÕES}

Analisando os resultados obtidos nessa pesquisa, podemos informar que: os alunos do curso de Pedagogia do polo estudado fazem uso da biblioteca digital da faculdade para obter informações para suas tarefas acadêmicas; além disso, os alunos conseguem perceber a importância de se entender qual a natureza da informação necessária para suas tarefas acadêmicas; conseguem identificar os tipos de fontes que fazem parte da biblioteca digital. Apesar de informarem dificuldades para utilização da biblioteca digital, essa se apresenta como uma importante fonte para busca de informações durante o curso.

Os alunos do curso pesquisado deveriam apresentar maior competência informacional no uso de bibliotecas digitais. Os dados relatados demonstram que a maioria tem acesso a equipamentos em casa e em outros lugares e fazem uso de diversos softwares em suas atividades, porém, o percentual de dificuldades que informam ter na utilização da biblioteca digital se mostra, no nosso entendimento, muito elevado tanto para utilizar o programa quanto para fazer a pesquisa.

O percentual de dificuldades apresentado pelos alunos pesquisados na utilização da biblioteca digital demonstra que há necessidade de se melhorar a relação desses alunos com a biblioteca digital e os recursos que ela apresenta. Apesar de o polo pesquisado possuir uma biblioteca do tipo convencional, essa não conta com o profissional específico para organização de seu acervo e nem para orientação do aluno na utilização das fontes oferecidas pela faculdade, sejam elas em formato impresso ou digital.

Destacamos a necessidade de maiores orientações para os alunos no que se refere à navegação no site, por via de links e sistemas de pesquisa da biblioteca digital, o que facilitaria a busca e recuperação de informações necessárias; embora tenhamos observado que o aluno tem acesso à orientação de usuário pelos bibliotecários da faculdade, com a oferta de curso através do "FAQ" e "Tutorial", disponibilizados na página da biblioteca digital da faculdade, além de um e-mail para contato com a equipe.

Quanto ao uso de bibliotecas convencionais e digitais, embora haja declaração de uso da biblioteca digital, quando algumas questões procuram detalhar o tempo de acesso à internet, o motivo de acesso e o uso de serviços, os números observados parecem pouco consistentes.

A escrita propiciou, ao longo da história, uma forma de criação de acervos de mensagens codificadas (informação e conhecimento) que pudessem ser acumuladas em determinados locais para uso de leitores em situações de manipulação presencial e física dos textos nas bibliotecas convencionais. A mudança na forma de registro não parecer ter interferido na maneira como as pessoas buscam informação; apesar do registro estar em formato digital, a procura e a utilização ainda seguem o modelo tradicional.

O advento das bibliotecas digitais tornou a difusão de textos e acesso a eles mais disponível e em maior escala. Mudou também a relação de autoria, possibilitando uma nova relação de leitor, texto e autor que necessita de novas formas de estudo, como na tentativa de Aarseth de desenvolver modelo de relação "ergódica" com o cibertexto. Assim, a contribuição da teoria ergódica para esse trabalho é reconhecer a existência de outras possibilidades para o operador se relacionar com o texto, ou seja, reconhecer as outras funções do operador. Além da função interpretativa, as funções explorativa, configurativa e textônica podem ser mais detalhadas em estudos posteriores sobre a relação do operador com os textos da biblioteca digital.

Vimos que os dados mostram a existência de um novo tipo de relação entre as pessoas e o conhecimento. Na oferta disponível para os alunos, encontram-se possibilidades de se tornarem protagonistas, entrando em 
fóruns e lendo, além da possibilidade de também postarem novos conteúdos, de usarem blogs para cooperativamente em interação receberem contribuições e influírem na direção do curso tomado pela discussão. Tudo isso pode ser feito a partir das escolhas que os participantes fizerem ao escrever seus comentários e perguntas.

Esta outra atitude apontaria para o desenvolvimento cooperativo de conhecimentos e paradigmas e para outro modo de estudar, aprender e criar conhecimentos que as novas gerações, os "nativos digitais", estão construindo. Mas, embora expostos a esse paradigma emergente, os participantes deste curso na modalidade $\mathrm{EaD}$ optaram por terem uma atitude predominantemente receptiva em relação à aquisição de informações para obtenção de diploma. Esta atitude pragmática não exclui ficar um resíduo de mudança de paradigma. Uma vez expostos ao novo paradigma, saberão mudar a direção do seu pensamento quando a situação contextual mudar.

Nesta pesquisa não foi investigado se esses alunos se tornam autores, mesmo que em forma de e-mails, fóruns, blogs ou wikis. Não foi investigado também se tem participação em jogos, como estabelece a teoria de Literatura ergódica. As inconsistências sugerem que além da competência informacional talvez haja outros fatores a pesquisar e que determinam o uso efetivo de biblioteca digital.

A formação do professor para o uso de tecnologias não deveria se restringir ao uso do computador e suas aplicações. Todo conhecimento obtido no aprendizado de uma tecnologia atual é reaproveitado para o aprendizado de uma nova tecnologia. O conhecimento tecnológico não é perdido quando surge uma nova mídia, ele é transformado. Acreditamos que a pouca utilização de tecnologia como ferramenta pedagógica no interior da escola não se deve exatamente à falta de conhecimento e utilização de tecnologia pelos professores.

Outros motivos vão desde o não preparo para utilização do computador como ferramenta pedagógica até dificuldades estruturais da escola, como: máquinas desatualizadas; falta de manutenção das máquinas que estão em uso; número reduzido de computadores em relação ao número de alunos por turma; e falta de estratégias que facilitem o uso do computador no interior da escola.

Consideramos que a antiga formação inicial dos professores não privilegiava a utilização de tecnologias como estratégia pedagógica, mas a formação em nível superior, atualmente, já prevê o uso de tecnologias, o que pode ser percebido pelas disciplinas que são oferecidas aos alunos dos cursos de formação, principalmente, os que são oferecidos na modalidade a distância, mesmo porque o formato do curso exige o uso do computador para o próprio curso.

Ao buscar compreender o processo de aquisição de conhecimento por professores em curso de EaD, algumas respostas foram encontradas. Contudo, essas respostas possibilitam novos questionamentos que trabalhos futuros poderão deixar mais claros. Enfim, há um campo muito vasto para pesquisas no campo da educação na modalidade $\mathrm{EaD}$ e acreditamos que nosso estudo seja apenas um aporte inicial.

\section{REFERÊNCIAS}

AARSETH, Espen J. Cibertexto: perspectivas sobre literatura ergódica. Lisboa: Pedra de Roseta, 2005. 229p.

BRASIL. Ministério da Educação. Secretaria de Educação a Distância. Referenciais de qualidade para educação superior a distância. Brasília, 2007. Disponível em:

<http://portal.mec.gov.br/seed/arquivos/pdf/legislacao/refead1.pdf >. Acesso em: 13 fev. 2011.

CASTELLS, Manuel. A sociedade em rede. 8. ed. São Paulo: Paz e Terra, 2005. 698 p. (A era da informação: economia, sociedade e cultura; v.1).

COSCARELLI, Carla Viana; RIBEIRO, Ana Elisa (Orgs). Letramento digital: aspectos sociais e possibilidades pedagógicas. Belo Horizonte: Ceale; Autêntica, 2007. 
CUNHA, Murilo Bastos. Das bibliotecas convencionais às digitais: diferenças e convergências. Perspectivas em Ciência da Informação, v.13, n.1, p. 2-17, 2008.

DUDZIAK, E. A. Information literacy: princípios, filosofia e prática. Ciência da Informação, Brasília, v.32, n. 1, p. 23-35, jan/abr. 2003.

MARTINS, Cristina de Matos. Um estudo do perfil textual de role playing games 'pedagógicos’. 2007.159f. Dissertação (Mestrado) - Faculdade de Filosofia, Letras e Ciências Humanas, Universidade de São Paulo, São Paulo, 2007.

PONGELUPE, Érica Gualberto. Informática nos cursos de Licenciatura em Matemática da Região Metropolitana de Belo Horizonte: uso informado pelos docentes. 2004. $216 f$. Dissertação (Mestrado em Tecnologia) Centro Federal de Educação Tecnológica, Belo Horizonte, 2004.

TAMMARO, Anna Maria; SALARELLI, Alberto. A biblioteca digital. Brasília: Briquet de Lemos, 2008.

Recebido em 28/o8/11. Aprovado em 22/12/11. 